\title{
CRÓNICA 2016 DE LA CORTE SUPREMA DE JUSTICIA ARGENTINA
}

\section{Argentina Supreme Court of Justice. Report 2016}

\author{
SERGIO DÍAZ RICCI' \\ Universidad Nacional de Tucumán \\ serdiricci@arnet.com.ar
}

Cómo citar/Citation

Díaz Ricci, S. (2017).

Crónica 2016 de la Corte Suprema de Justicia argentina. Anuario Iberoamericano de Justicia Constitucional, 21, 187-209. doi: https://doi.org/10.18042/cepc/aijc.21.08

\section{SUMARIO}

I. PANORAMA GENERAL. II. DERECHOS FUNDAMENTALES: 1. Derechos de los usuarios de servicios públicos. Audiencia pública previa. 2. Derecho ambiental. Amparo ambiental: 2.1. Caso de represas hidroeléctricas. 2.2. Principio precautorio en materia ambiental. 2.3. Evaluación de impacto ambiental. 2.4. Protección de fauna silvestre. 2.5. Caso contaminación del Riachuelo. 3. Derecho de huelga. 4. Derecho preferente de los niños. Habeas corpus colectivo-correctivo. III. OTROS CASOS: 1. Extradición de terrorista. 2. Sistema de control difuso de constitucionalidad. 3. Conflicto entre poderes provinciales. IV. CASO NISMAN. BIBLIOGRAFía.

\section{PANORAMA GENERAL}

Como siempre recordamos y vamos a reiterar, esta crónica tiene el propósito de hacer una reseña de la jurisprudencia constitucional argentina más

1 Catedrático de Derecho Constitucional, Universidad Nacional de Tucumán, Universidad de San Pablo-Tucumán. 
relevante durante el año 2016, circunscrita a las sentencias que dictadas por la Corte Suprema de Justicia de Argentina (en adelante, CSJA) como máximo y último tribunal del sistema del control jurisdiccional de la Constitución de la Nación Argentina (CA).

Consideramos conveniente repetir dos notas típicas del sistema de control de constitucionalidad federal en Argentina: por un lado, como regla general la acción debe interponerse siempre ante un juez de primera instancia (control difuso con alcance inter partes) y, por el otro, solo existen cuatro vías procesales para obtener un pronunciamiento judicial en materia constitucional: acción de amparo, habeas corpus, acción declarativa de constitucionalidad y, dentro de un juicio común, cuando se plantea una cuestión de constitucionalidad federal.

Por tanto, los casos que vamos a citar aquí son sentencias («fallos», en la jerga judicial argentina) dictadas por la CSJA que llegan a su conocimiento por medio del recurso extraordinario contra sentencias originadas en cualquiera de los cuatro procesos arriba indicados. Estos fallos, por tratarse de pronunciamientos cimeros, tienen indudable trascendencia constitucional.

Muy excepcionalmente (solo en dos casos) puede intervenir la CSJA de manera directa como tribunal de única instancia aunque siempre debe emplearse cualquiera de las cuatro vías antes señaladas. Por regla general, la Corte Suprema argentina únicamente revisa sentencias definitivas dictadas por los últimos tribunales de la causa, federales o provinciales, una vez agotadas las vías procesales existentes en cada jurisdicción. En consecuencia, únicamente llega a conocimiento de la CSJA la apelación de esas sentencias finales por vía de recurso extraordinario. Anótese la siguiente particularidad: este recurso se presenta ante el mismo tribunal que dictó esa última sentencia que se cuestiona. De este modo se evita que el recurrente tenga que desplazarse a la capital federal, o sea, a la ciudad de Buenos Aires para presentar el escrito de recurso extraordinario. Es entonces, este mismo último tribunal quien recibe el recurso extraordinario pero ahora se limita a analizar, no vuelve ya a ver el fondo del asunto que ha quedado cerrado, sino solo el cumplimento de dos requisitos: que haya cuestión federal suficiente y que la decisión haya sido en contra del derecho federal invocado. Si considera que se dan estas condiciones, remite el expediente a la CSJA a Buenos Aires, pero si entiende que no se reúnen estos dos recaudos, no habilita el recurso extraordinario. Su ocurriese esto último el afectado dispone de la posibilidad de ir directamente a la CSJA en Buenos Aires a través del recurso de hecho (también denominado recurso directo o de queja) en reclamo contra la denegatoria hecha por algún tribunal nacional final o un tribunal superior de provincia de no dar curso al recurso extraordinario.

Las sentencias de la CSJA se publican en una colección impresa que se denomina Fallos. Su publicación comenzó en 1861, con el tomo I de Fallos, 
que contiene desde la primera sentencia de fecha 15 de octubre de 1863 hasta la actualidad sin solución de continuidad. Sin embargo, a partir de la Acordada 37/2003, en esta colección Fallos, solo se publican las sentencias de mayor trascendencia emitidas por el CSJA. Del año 2016, estas sentencias se encuentran publicadas en Fallos tomo 339, en dos volúmenes, volumen I (924 pp. hasta 12 de julio) y volumen II (pp. 951-1837 del 27 de diciembre de 2016).

Hechas estas aclaraciones necesarias previas, podemos comenzar señalando que la gran novedad del año 2016 fue cobertura de los dos cargos vacantes en la Corte Suprema de Justicia argentina. El año 2015 terminó con una CSJA menguada en su composición, con solo tres de sus cinco integrantes: Ricardo Lorenzetti, Elena Highton de Nolasco y Juan Carlos Maqueda. El recientemente electo presidente de la nación, Mauricio Macri, presentó ante el Senado federal el pedido de acuerdo parlamentario a los Dres. Horacio Rosatti y Carlos Rosenkrantz para los dos cargos, conjuntamente ${ }^{2}$. De este modo la CSJA quedó completada su integración. Por cierto, estas nuevas incorporaciones luego de doce años significaron un notable cambio en la CSJN no solo en su composición sino, como se verá reflejado en las sentencias, en la jurisprudencia constitucional.

\section{DERECHOS FUNDAMENTALES}

\section{DERECHOS DE LOS USUARIOS DE SERVICIOS PÚBLICOS. AUDIENCIA PÚBLICA PREVIA}

Aumento tarifario. Caso Centro de Estudios para la Promoción de la Igualdad y la Solidaridad y otros vs. Ministerio de Energía y Minería s/ amparo colectivo (Fallos 339: 1098 del 18/08/2016).

Una de las sentencias de mayor impacto mediático que marcó la presentación de la nueva conformación de la Corte Suprema fue relativa al elevando aumento de la tarifa de suministro de gas dispuesta por el Gobierno.

2 En el sistema argentino de nombramiento de integrantes de la CSJA, es análogo al de Estados Unidos: el presidente presenta una propuesta de un nombre al Senado, quien debe prestar conformidad con el voto de una mayoría de $2 / 3$ de los miembros presentes. Luego el presidente formaliza la designación (art. 75 inc. $4 .^{\circ} \mathrm{CA}$ ). El Senado argentino prestó acuerdo el 15 de junio de 2016. Rosatti (a la sazón presidente de la Asociación Argentina de Derecho Constitucional) asumió en la Corte el 29 de junio y Rosenkrantz lo hizo el 22 de agosto de 2016. 
El caso se inició como una acción de amparo colectivo presentada por una asociación de usuarios del servicio público de gas contra un par de resoluciones del Ministerio de Energía que dispuso un importante aumento en la tarifa de trasporte y distribución del gas natural cuyo suministro, en Argentina, constituye un servicio público nacional brindado por empresas concesionarias ubicadas en distintas partes del país.

Se reclamaba el derecho del usuario del servicio de gas a intervenir con carácter previo al aumento tarifario en resguardo de sus intereses, invocándose el derecho a una información adecuada y veraz que garantiza el art. 42 CA. Como se trata de un amparo colectivo el juez de primera instancia interviniente procedió a la inscripción del proceso en el Registro Público de Procesos Colectivos creado por la CSJA.

Esta suba tarifaria dio lugar a la presentación de un sinnúmero de acciones judiciales en distintos tribunales federales del país (pues se trata de un servicio público nacional), los que de un modo u otro confluyeron en la CSJA quien, con su pronunciamiento, procuró dar una respuesta unificada a los diversos planteos por el mismo tema.

La causa llega a conocimiento de la CSJA por recurso extraordinario presentado por el Estado Nacional contra la sentencia de cámara que había dispuesto que las resoluciones cuestionadas eran nulas fundada en que se había omitido llevarse a cabo una audiencia pública previa.

La Corte argentina en su pronunciamiento procede a diferenciar dos tipos de usuarios: los residenciales y los no residenciales. Respecto de los primeros interpretó que se halla comprometida la garantía constitucional de acceso a la justicia porque "en materia tarifaria la participación de los usuarios de un servicio público no se satisface con la mera notificación de una tarifa ya establecida, ya que es imperativo constitucional garantizar la participación ciudadana en instancias públicas de discusión y debate susceptibles de ser ponderadas por la autoridad de aplicación al momento de la fijación del precio del servicio». Esta conclusión va a tener como sustento constitucional que

La participación de los usuarios con carácter previo a la determinación de la tarifa constituye un factor de previsibilidad, integrativo del derecho constitucional a una información 'adecuada y veraz' (art. 42 CA) y un elemento de legitimidad para el poder administrador, responsable en el caso de garantizar el derecho a la información pública, estrechamente vinculado al sistema republicano de gobierno (art. $1^{\circ}$ CA), al mismo tiempo que otorga una garantía de razonabilidad para el usuario y disminuye las estadísticas de litigación judicial sobre las medidas que se adoptan.

Es interesante la vinculación que la CSJA establece entre el acceso al gas domiciliario (muy difundido su empleo para calefacción en Argentina) con el 
concepto de salud y vida digna en estos términos: «El servicio público domiciliario de gas es un servicio indispensable para la salud y la vida digna", citando en apoyo a la observación general 4 del Comité de Derechos Económicos Sociales y Culturales de la ONU sobre «derecho a una vivienda adecuada (art. 8.b)» referido en el art. 11.1 del Pacto Internacional de Derechos Económicos, Sociales y Culturales (que en Argentina goza de jerarquía constitucional en virtud de lo dispuesto por el art. 75 inc. 22 CA), para concluir que «el servicio público domiciliario de gas es un servicio indispensable para la salud y la vida digna, que está expresamente comprendido dentro de la noción de vivienda adecuada desarrollada por el sistema de protección de derechos humanos».

Finalmente, la CSJA sobre el fundamento que se han incumplido disposiciones de la ley 24076 de gas natural — que requiere la obligatoriedad de la convocatoria a la audiencia pública cuando media una modificación en la remuneración de los concesionarios de los servicios - va a declarar la nulidad de las resoluciones de incremento tarifario, pero circunscribe el beneficio al colectivo de usuarios residenciales del servicio de gas natural (se excluye, por tanto, a los usuarios no residenciales) en razón de haberse omitido el requisito de la audiencia previa, pues pone de relieve «la relevancia de la audiencia pública que configura una instancia de participación ciudadana que favorece la democratización de las decisiones, la formación de consensos, la transparencia y la publicidad de los actos y los procedimientos, lo que, en definitiva, fomenta el control social».

También, es notable la atención que otorga la CSJA a la regulación de acciones de incidencia colectiva en casos como la presente. A fin de evitar que la dispersión y proliferación de acciones colectivas menoscabe la unidad jurisdiccional y la seguridad jurídica, la CSJA había creado en su ámbito un Registro Público de Procesos Colectivos (Acordada 32/2014), y establecido un «reglamento de actuación en procesos colectivos» (por Acordada 12/2016) con el fin de unificar el trámite en el primer tribunal que hubiese intervenido $y$ de ese modo asegurar eficazmente el inevitable efecto expansivo que tiene una sentencia definitiva de este tipo pasada en autoridad de cosa juzgada en esta clase de procesos.

\section{DERECHO AMBIENTAL. AMPARO AMBIENTAL}

La Corte argentina durante el año 2016 se mostró particularmente activa en asuntos ambientales.

\subsection{Caso de represas hidroeléctricas}

Un caso de trascendencia fue el amparo ambiental por la construcción de dos represas hidráulicas en la Patagonia (caso Asociación argentina de abogados 
ambientalistas de la patagonia vs. Santa Cruz provincia de y otro, s/Amparo ambiental; Fallos 339-I, p. 515).

Este es un caso en cierto modo análogo al anterior pero en materia de protección ambiental. Se inicia con una acción de amparo ambiental tendente a impedir el comienzo de la construcción de dos represas localizadas en la provincia demandada que conlleva trabajos de una magnitud considerable, con gran potencial para modificar el ecosistema de toda la zona. El amparo fue presentado por los accionantes directamente en los estrados de la CSJA, invocándose para ello la competencia originaria y exclusiva que le otorga la CA en causas en que sea parte un Estado provincial. La Corte, que ha asumido una posición proactiva en materia ambiental, aunque difirió la definición de su competencia para más adelante, sin embargo, dispuso como medidas preventivas a tenor de las facultades que confiere la Ley General del Ambiente (Ley 25 675) y la ley nacional de protección de glaciares (Ley 26639 de presupuestos mínimos) en razón de su situación como primer tribunal interviniente. En función de estas potestades, en aplicación del principio precautorio (art. 4 LGA) va ordenar algunas medidas informativas para conocer si se llevaron a cabo el estudio de impacto ambiental y la audiencia o consultas públicas exigidas por la Ley General del Ambiente, por entender que «existe evidencia de obras con suficiente relevancia como para alterar un amplio ecosistema, por lo que se hace necesario asegurar la sustentabilidad del desarrollo que se pretende... que la efectividad que se reclama para todos los derechos fundamentales, también debe ser predicada respecto de los de incidencia colectiva y en particular del ambiente» por cuanto «la CA tutela al ambiente de modo claro y contundente y esta Corte Suprema ha desarrollado esa cláusula de un modo que permite admitir la existencia de un componente ambiental del estado de derecho".

Esta preferente preocupación por la temática ambiental había llevado a la CSJA a crear en el año 2014 la Oficina de Justicia Ambiental (Acordada 1/14) con funciones de capacitación, investigación, recolección de datos y de representación de la misma corte en la Comisión de Ambiente y Sustentabilidad que fue creada por Acordadas 35/2011 y 16/2013 la que, además, estableció el Sistema de Gestión Ambiental y la Norma de Gestión Ambiental para la Corte Suprema de Justicia de la Nación.

\subsection{Principio precautorio en materia ambiental}

Llega conocimiento de la CSJA el rechazo de una medida cautelar, solicitada por el afectado por un emprendimiento minero en terrenos de su propiedad y denegada por el juez federal de primera instancia, y luego confirmada por la Cámara federal (caso Recursos de hecho deducidos por el Fiscal General 
Federal de Tucumán y por la actora en la causa Cruz, Felipa y otros vs. Minera Alumbrera Limited y otro s/ sumarísimo; Fallos 339:142, 23/02/2016).

La medida cautelar solicitada por la actora tenía por objeto de que se ordene la suspensión inmediata de la actividad minera llevada a cabo en los yacimientos mineros ubicados en terrenos de su propiedad, en la localidad de Andalgalá, provincia de Catamarca, hasta tanto se realicen informes periciales in situ para medir el alcance de la contaminación y degradación del medio ambiente producido por las filtraciones originadas en el dique de colas - entre otros factores contaminantes-, y hasta tanto las demandadas acrediten haber cumplido con la contratación de un seguro de cobertura con entidad suficiente para garantizar el financiamiento de la recomposición del daño, según lo dispone el art. 22 de la Ley General del Ambiente 25675.

Mientras los tribunales inferiores entendieron que la aceptación de la medida cautelar significaba un pronunciamiento sobre el fondo del asunto, la demandante sostuvo que esta denegatoria causa un gravamen concreto y actual de imposible reparación ulterior, contraviniendo el principio preventivo y precautorio que rige en materia ambiental.

Aquí la CSJA se aparta del principio que solo revisa sentencias definitivas, porque entiende que en este caso prevalece el interés superior ambiental que exige anticiparse al daño por imperio del principio preventivo y precautorio, establecido por el art. 4 de la Ley General del Ambiente 25 675. La Corte hizo una excepción al principio que los recursos extraordinarios solo se ocupan de sentencias definitivas por cuanto, entendió, que el rechazo de la medida cautelar es susceptible de producir un agravio al medio ambiente que, por su magnitud y circunstancias de hecho, puede ser de tardía, insuficiente o de imposible reparación ulterior.

Citando como precedente el caso Asociación Multisectorial del Sur en Defensa del Desarrollo Sustentable vs. Comisión Nacional de Energía Atómica (Fallos 333:748, 26/05/2010) recuerda que el análisis «debe efectuarse desde una moderna concepción de las medidas necesarias para la protección del medio ambiente, pues el art. 4 de esa ley introduce en la materia los principios de prevención del daño ambiental y de precaución ante la creación de un riesgo con efectos desconocidos y por tanto imprevisibles». De esto se derivan dos consecuencias:

a) Que el régimen legal el ambiente autoriza que en cualquier estado del proceso, pueda solicitarse medidas de urgencia necesarias para ordenar, conducir o probar los hechos dañosos en el proceso, a fin de proteger efectivamente el interés general, aun con carácter de medida precautoria, y que el juez también podrá disponerlas sin petición de parte, aun sin 
audiencia de la parte contraria, prestándose debida caución por los daños y perjuicios que pudieran producirse.

b) Que a la luz del principio precautorio, cuando haya peligro de daño grave e irreversible la ausencia de información o certeza científica no deberá utilizarse como razón para postergar la adopción de medidas eficaces, en función de los costos, para impedir la degradación del ambiente (véase art. 4 de la Ley 25 675), en consecuencia, interpreta la Corte que los tribunales inferiores omitieron de realizar un balance provisorio entre la perspectiva de la ocurrencia de un daño grave e irreversible y el costo de acreditar el cumplimiento de las medidas solicitadas. En conclusión, la CSJA afirma que «el juicio de ponderación al que obliga la aplicación del principio precautorio, exige al juez considerar que todo aquel que cause daño ambiental es responsable de restablecer las cosas al estado anterior a su producción». Sobre esta base, resolverá que la denegatoria de la medida cautelar dispuesta por los tribunales inferiores, al no considerar las pruebas aportadas por la actora, afecta de modo directo e inmediato el derecho al debido proceso adjetivo (art. $18 \mathrm{CA}$ ), por lo que corresponde su descalificación como acto jurisdiccional en los términos de la doctrina sobre arbitrariedad de sentencias, consecuentemente, deja sin efecto la sentencia del inferior y ordena que los autos vuelvan al tribunal de origen a fin de que dicte un nuevo pronunciamiento con arreglo a lo resuelto.

\subsection{Evaluación de impacto ambiental}

Aprobación previa. Otro caso análogo en materia ambiental, esta vez relacionado con un emprendimiento minero, tuvo lugar por un amparo interpuesto por unos vecinos de una localidad de la provincia de Catamarca, por considerar que no se había cumplimentado con los recaudos exigidos para la correcta aprobación del Informe de Impacto Ambiental presentado por la empresa minera. (Caso Martínez, Sergio Raúl vs. Agua Rica LLC Suc Argentina y su propietaria Yamana Gold Inc. y otros. s/ acción de amparo; Fallos 339:201, 02/03/2016).

El amparo fue rechazado por el juez provincial de primera instancia, lo que fue ratificado en segunda instancia por la Cámara de Apelaciones y, también, confirmado por el Tribunal Superior de la provincia. Llegado a conocimiento de la CSJA por recurso de queja, va a revocar la sentencia y exigir un nuevo pronunciamiento que analice las causales por la que se cuestionó la validez de la aprobación que la Secretaría competente hizo del Informe de Impacto Ambiental presentado por la explotación minera. La sentencia de la CSJA va a ocuparse 
por analizar la naturaleza de la acción de amparo y su relevancia en materia ambiental. Sobre lo primero dirá «que si bien la acción de amparo no está destinada a reemplazar los medios ordinarios para la solución de controversias, su exclusión no puede fundarse en una apreciación meramente ritual e insuficiente de las alegaciones de las partes, toda vez que la citada institución tiene por objeto una efectiva protección de derechos más que una ordenación o resguardo de competencias», precisamente, en relación a lo segundo, al empleo de la acción de amparo en materia ambiental, expresa que «no puede desconocerse que en asuntos concernientes a la tutela del daño ambiental, las reglas procesales deben ser interpretadas con un criterio amplio que, sin trascender el límite de su propia lógica, ponga el acento en su carácter meramente instrumental de medio a fin, que en esos casos se presenta una revalorización de las atribuciones del tribunal al contar con poderes que exceden la tradicional versión del juez espectador» y, poniendo énfasis en el principio preventivo-precautorio en cuestiones ambientales finaliza destacando que «es importante señalar que en cuestiones de medio ambiente, cuando se persigue la tutela del bien colectivo, tiene prioridad absoluta la prevención del daño futuro. En ese sentido,» — concluye aclarando la CSJA - «la realización de un estudio de impacto ambiental previo al inicio de las actividades no significa una decisión prohibitiva del emprendimiento en cuestión, sino antes bien una instancia de análisis reflexivo, realizado sobre bases científicas y con participación ciudadana».

Por un lado, la CSJA interpretó que la decisión del Tribunal Superior de provincia - al no considerar los cuestionamientos de la actora sobre la validez de la resolución de la Secretaría de Minería de la provincia que aprobó el Informe de Impacto Ambiental en forma condicionada- era manifiestamente ilegal y arbitrario por tanto, esa denegatoria no constituye un acto jurisdiccional válido con arreglo a la doctrina de la arbitrariedad de sentencias. Y, por otro lado, considera que el amparo constituye una vía idónea para tutelar esta pretensión ambiental y evitar así un daño eminente al medio ambiente. La resolución de la Corte fue devolver la causa para que el tribunal de origen analice el cumplimiento de los recaudos legales en materia de evaluación de impacto ambiental previo.

\subsection{Protección de fauna silvestre}

La Unidad Fiscal de Investigaciones en Materia Ambiental (UFIMA), perteneciente al Ministerio Público, presentó una denuncia contra unos sujetos que ofrecen (a través de una página web) la caza de distintas especies protegidas de la fauna silvestre en un coto de caza ubicado en la localidad de Tandil, que no está inscripto ni habilitado por los organismos, en infracción a la Ley nacional de protección y conservación de la fauna silvestre (Ley 22 421). 
En el sitio web www.miaventura.com/caza/cotos.html se ofrece la caza de los siguientes ejemplares de la fauna silvestre: ciervos colorados, ciervos axis, antílopes de la India, pumas y cauquenes, y, además, servicios de «traslado campo/ aeropuerto, guía profesional, alquiler/préstamo de armas, provisión de municiones, despostado de piezas, preparación de trofeos».

Estas excursiones de caza de animales silvestres (cauquenes, gansos, tórtolas, palomas, patos "maicero" y "picazo», carpinchos, ciervos axis, antílopes, búfalos de agua, carneros de cuatro cuernos, chanchos cimarrones y jabalíes) se ofrecen en las provincias de Buenos Aires, Santa Fe, Córdoba y Entre Ríos. Esta actividad se encuentra prohibida respecto de algunos ejemplares y reglada en relación a otros, incurriéndose en una infracción a la Ley nacional de protección y conservación de la fauna silvestre (Ley 22.421).

El este asunto (caso Club de caza de tandil s/ Infracción Ley 22421 (art. 25); Fallos 339-1, p. 160) la CSJA tuvo que resolver una cuestión de competencia: si la investigación de estos delitos corresponde a la jurisdicción provincial (como es la regla general) o, si en este caso, es de competencia federal. Si bien la CSJA ya había fijado posición (Fallos: 323: 2738 y 329: 2817, 6056, entre otros), que en materia de delitos esa ley no corresponde la jurisdicción federal, sin embargo, en este caso se ve directamente afectado un interés de la nación que abre la competencia del fuero federal.

Es interesante la interpretación que realiza la Corte sobre este tipo de hechos (caza de especies migratorias protegidas) en relación a las facultades que le confiere la Ley General del Ambiente (Ley 25 675, art. 7) y en aplicación de convenciones internacionales sobre la materia. En efecto, advierte el tribunal que el Estado nacional ha puesto un marcado interés en la protección y preservación del ave cauquén en todas sus especies ("colorado", "cabeza gris», "común», "guayata» y "caranca»), a punto tal que su caza y captura se encuentran prohibidas en todo el territorio del país, como también vedados el tránsito interprovincial, el comercio en jurisdicción federal, la importación y la exportación de sus ejemplares vivos, productos y subproductos. La resolución de la Secretaría de Ambiente y Desarrollo Sustentable de la Nación sobre conservación de la fauna se ha incluido ciertas especies del ave cauquén (cabeza gris, colorado y común) como especies migratorias «vulnerables», «amenazadas» $\mathrm{y}$ «en peligro crítico de extinción», respectivamente; y, específicamente, el tipo «cauquén colorado» se encuentra calificada como especie en peligro por la Convención sobre la Conservación de las Especies Migratorias de Animales Silvestres (Bon, 23 de junio de 1979, y aprobada por Argentina por Ley 23 918). También, otros ejemplares de la fauna silvestre referidos se encuentran incluidas en los "Apéndices I, II y III", según su grado de amenaza, de la Convención sobre el Comercio Internacional de Especies Amenazadas de Fauna y Flora (CITES) aprobada por Ley 22344. 
Por añadidura, además, se ofrece el servicio de despostado de piezas y la preparación de trofeos, por lo que surge el interrogante si se exportarían clandestinamente productos y subproductos provenientes de la caza furtiva, vulnerando los controles aduaneros.

Por todas las características del hecho, la CSJA se aparta del principio general para resolver que la causa no es de jurisdicción provincial, sino compete a la justicia federal con jurisdicción en el lugar donde se prestarían los servicios intervenir en los hechos.

En la misma fecha (23 de febrero) se pronunció en el mismo sentido en dos casos análogos (N.N. s/ Infracción ley 22.421, Fallos 339-I, p. 17; y U.F.I.M.A. s/ Denuncia, Fallos 339-I, p. 175).

\subsection{Caso contaminación del Riachuelo}

Caso Mendoza, Beatriz Silvia y otros vs. Estado nacional y otros s/ Daños y perjuicios (daños derivados de la contaminación ambiental del Río Matanza Riachuelo). En este caso emblemático de la CSJA cuya finalidad es la descontaminación de la cuenca hídrica Matanza-Riachuelo, se produjeron algunas novedades.

Por aquella Sentencia del 8 de julio de 2008 (Fallos: 331: 1622), la CSJA había dispuesto que un cuerpo colegiado compuesto por cinco organizaciones no gubernamentales, bajo la coordinación del defensor del pueblo, emita informes especiales indicando medidas de control a adoptar por el Tribunal respecto de los establecimientos industriales, agropecuarios, servicios existentes en la cuenca, residuos y basurales, agua potable, saneamiento cloacal, vivienda y salud. El apoderado legal de la Defensoría del Pueblo presentó un par de informes aprobados en sendas reuniones de dicho cuerpo colegiado celebradas los días 18 de diciembre de 2014 y 6 de julio de 2015. Sin embargo, el cargo de defensor del pueblo se encuentra vacante desde el 2009, como asimismo se han vencido los mandatos de los defensores adjuntos en el 2013. Por estas razones, por sentencia del 1 de julio de 2016 (Fallos 399: 1562), la CSJA consideró que el letrado apoderado que suscribe las presentaciones antes referidas, carece de facultades para invocar la representación procesal de la institución en tanto, al tiempo de formalizarlas, esta se encontraba acéfala. Por subsanar esta ausencia, ante la falta de cobertura del cargo de defensor del pueblo de la nación por el Congreso, dispuso que mientras tanto, dicho cuerpo colegiado deberá deliberar y adoptar sus decisiones por mayoría absoluta. Asimismo, resolvió exhortar al Congreso de la nación (a la Cámara de Diputados y al Senado de la nación) para que en el marco de sus respectivas atribuciones constitucionales, en un plazo razonable, cumpla con su deber constitucional, el más breve lapso posible, y designe al defensor del pueblo de la nación. 
Hacia fin de año la CSJA convoca a una audiencia pública a fin de evaluar el Plan Integral de Saneamiento Ambiental (PISA) que tiene tres objetivos simultáneos: 1) la mejora de la calidad de vida de los habitantes de la cuenca; 2) la recomposición del ambiente en la cuenca en todos sus componentes (agua, aire y suelos), y 3) la prevención de daños con suficiente y razonable grado de predicción; fijando objetivos intermedios, sujetos a control periódico de los resultados. Este programa debe ser desarrollado por la Autoridad de Cuenca Matanza Riachuelo (ACUMAR, Ley 26.168) concurrentemente con el Estado nacional, la provincia de Buenos Aires y la Ciudad Autónoma de Buenos Aires.

De la audiencia, que tuvo lugar el 30 de noviembre de 2016, se constataron deficiencias en el cumplimiento del programa. Por esta razón, mediante sentencia del 27 de diciembre de 2017 (Fallos 399: 1795), ordeno a la ACUMAR que (1) en el plazo perentorio de tres meses establezca un sistema de indicadores que, conforme a los criterios internacionales de medición disponibles, permita medir el nivel de cumplimiento de los objetivos fijados por la sentencia en ejecución; (2) eleve el 1 de marzo de 2017 —un informe que detalle en forma sintética y precisa- un calendario con los objetivos de corto, medio y largo alcance para cada uno de los objetivos del PISA, con indicación del plazo de cumplimiento de cada uno de ellos; (3) presentar, con la periodicidad que indiquen los jueces de ejecución, informes detallados y de extensión moderada sobre el avance de cada uno de los objetivos del PISA poniendo especial énfasis en: a) control de la contaminación industrial; b) saneamiento de basurales y limpieza de márgenes; c) expansión de la red de agua potable y cloacas; d) relocalización de villas y asentamientos precarios: debiéndose acelerar el cumplimiento del Convenio Marco del Programa de Urbanización de Villas y Asentamientos precarios celebrado el 23/09/2010 (2. ${ }^{a}$ etapa). En particular, la Ciudad Autónoma de Buenos Aires con carácter prioritario deberá avanzar en la liberación del camino de sirga a la altura de las villas 21-24 y 26, con la consiguiente relocalización de los habitantes; e) plan sanitario de emergencia (elaborar el Mapa de Riesgo Sanitario Ambiental y fortalecer el Programa de Salud Ambiental Infantil); f) calidad ambiental: informar las etapas a corto, mediano y largo plazo del proceso de revisión y modificación de la normativa referentes a límites de vertido, calidad y usos del agua, agente contaminante, calidad de aire bajo el principio de no regresión. A efectos de hacer cumplir estas mandas, termina ordenando a los titulares del Juzgado Nacional de Primera Instancia en lo Criminal y Correccional Federal n. ${ }^{\circ} 12$ y del Juzgado Federal de Primera Instancia en lo Criminal y Correccional n. ${ }^{\circ} 2$ de Morón que refuercen la supervisión e intensifiquen el control en el cumplimiento de los objetivos del PISA. 
Con fecha 27 de diciembre de 2016 la CSJA en respuesta a un par de oficios remitidos por el asesor tutelar ante la Cámara de Apelaciones en lo Contencioso Administrativo y Tributario de la Ciudad Autónoma de Buenos Aires, en representación de niños, niñas y adolescentes pertenecientes a grupos familiares que residen en el camino de costero de las villas 21-24 y 26 de la ciudad de Buenos Aires. En dichas presentaciones señala el incumplimiento de los plazos del cronograma de relocalización de los grupos familiares que residen a orillas del Riachuelo que, en algunos casos, lleva más de cuatro años de demora. También señala que, además, de la vulneración del derecho a una vivienda adecuada se agrega la violación del derecho a la salud y a un ambiente sano de sus representados. Sobre este punto acompaña el Informe Preliminar de la Evaluación Integral de Salud en Áreas de Riesgo (EISAR) llevado a cabo por la Autoridad de Cuenca Matanza Riachuelo (ACUMAR) donde se estableció que el 24,5\% de los menores de seis años analizados en la villa 21-24 y el $17 \%$ de ese universo en la villa veintiséis obtuvieron valores de plomo en sangre superiores al valor de referencia vigente que la Academia Nacional de Medicina recomienda en base a estudios toxicológicos internacionales que evalúan su peligrosidad. La Corte dicta sentencia donde afirma la responsabilidad en la demora de la relocalización y compromete al Estado de la Ciudad Autónoma de Buenos Aires y al Estado nacional condenados en este proceso. En consecuencia, remite al Juzgado Federal en lo Criminal y Correccional n. ${ }^{\circ}$ 2 de Morón esta presentación, en cumplimiento a lo dispuesto por la Corte que por sentencia del 19 de diciembre de 2012 (Fallos 399: 1793) dispuso que «los magistrados designados a cargo de la ejecución de la sentencia definitiva en la presente causa deberán, en el marco de sus respectivas competencias, hacer especial énfasis en la erradicación y relocalización de barrios de emergencia y asentamientos poblacionales precarios».

\section{DERECHO DE HUELGA}

Caso Recurso de hecho deducido por la demandada en la causa Orellano, Francisco Daniel vs. Correo Oficial de la República Argentina S.A. s/ juicio sumarísimo (Fallos 339-I, pp. 767ss.).

El asunto se origina por el despido de un trabajador de la empresa concesionaria del servicio público de correo oficial. El afectado demandó a la empleadora por considerar ilegítimo el despido porque fue motivado por su participación en una medida de huelga, por tanto, solicitó que se declarara la invalidez del despido dispuesto por la empleadora por tratarse de una medida discriminatoria que contraviene la ley antidiscriminación (Ley 23.592).

La empresa postal demandada, por su parte, reconoce que despidió al actor por su participación en medidas de fuerza que para la empleadora eran 
ilegítimas porque no contaron con el aval de los sindicatos que representaban al personal.

Tanto el Juzgado de Primera Instancia como la Cámara de Apelaciones hicieron lugar al reclamo ordenando que el empleado sea reinstalado en su puesto de trabajo y a abonarle los salarios caídos, pues consideraron que el trabajador había sido víctima de un trato discriminatorio adoptado por la empresa como represalia por su participación en medidas legítimas de acción gremial.

Llegado el caso a la Corte la cuestión debatida giró sobre la titularidad del sujeto facultado a promover una huelga como derecho consagrado por el art. 14 bis CA.

La interpretación de la CSJA fue que la normativa federal solamente confiere el derecho de declarar una huelga a las asociaciones profesionales $y$, además, que el único requisito que establece el art. 14 bis CA para el ejercicio de los derechos sindicales por parte de las organizaciones de trabajadores es el de su simple inscripción en un registro especial. En suma: el legítimo ejercicio del derecho de huelga está subordinado a que el sujeto que la dispone haya cumplido con ese recaudo de inscripción.

Sin embargo, la medida de fuerza en cuestión no había sido dispuesta por una asociación profesional que cuente con la debida inscripción, sino por iniciativa de un grupo informal de trabajadores, lo que tornó en ilegítima la medida.

El caso sirve de ocasión a la CSJA para desarrollar su interpretación sobre ciertas facetas del derecho de huelga: «El ejercicio del derecho de huelga exhibe dos facetas. Una individual que se identifica con el derecho del trabajador singular de adherirse o no a una huelga declarada; y otra indudablemente colectiva, pues fijar reivindicaciones, declarar o poner fin a la huelga, o negociar la solución del conflicto son atribuciones que necesariamente se ejercen a través de una agrupación de trabajadores». En este sentido sostiene que la huelga debe considerarse como un acto colectivo de una agrupación de trabajadores que, a través de una deliberación, resuelve declararla en tutela de sus intereses. Por tanto, la proclamación de la huelga es una condición previa para que surja el derecho del particular a abstenerse del trabajo o a retacearlo, entendido como el derecho subjetivo del trabajador de realizarla.

Seguidamente, la CSJA se explaya señalando que el ejercicio del derecho de huelga exhibe dos facetas. Una individual que se identifica con el derecho del trabajador singular de adherirse o no a una huelga declarada; y otra indudablemente colectiva, pues fijar reivindicaciones, declarar o poner fin a la huelga, o negociar la solución del conflicto son atribuciones que necesariamente se ejercen a través de una agrupación de trabajadores. 
Interpreta, en suma, que el ejercicio de esta última dimensión colectiva del derecho de declarar una huelga condiciona el ejercicio del derecho individual de adherirse o no a ella en un sentido material y en un sentido formal. En un sentido material, porque no es posible adherirse a una huelga no convocada. Y en un sentido formal, porque el ejercicio individual será legítimo si legítima fuese la convocatoria de la huelga. Indaga, luego, la génesis del art. 14 bis introducido por la reforma constitucional de 1957 para llegar a concluir que el constituyente dejó bien en claro que el derecho a declarar una huelga es de carácter gremial y no individual.

También acude, para abonar su posición, al Convenio 87 - sobre la libertad sindical y la protección del derecho de sindicación- de la Organización Internacional del Trabajo (OIT), a la opinión del Comité de Libertad Sindical y de la Comisión de Expertos en Aplicación de Convenios y Recomendaciones que son órganos instituidos para el control de la aplicación de las normas de la OIT. En especial cita al Comité de Libertad Sindical de la OIT que manifestó que «no parece que el hecho de reservar exclusivamente a las organizaciones sindicales el derecho de declarar una huelga sea incompatible con las normas establecidas en el Convenio núm. 87». En el mismo sentido se manifiestan las normas del derecho internacional de los derechos humanos que en nuestro país gozan de jerarquía constitucional o supra legal: el Pacto Internacional de Derechos Económicos, Sociales y Culturales (art. 8.d; id. el Comité de Derechos Económicos, Sociales y Culturales como intérprete autorizado del Pacto). Más trascendencia adquiere la cita expresa del art. 26 de la Convención Americana sobre Derechos Humanos en virtud de la cual se recurre a la Carta de la Organización de los Estados Americanos (art. 45 inc. c) y, especialmente, al Protocolo Adicional a la Convención Americana sobre Derechos Humanos en materia de Derechos Económicos, Sociales y Culturales — Protocolo de San Salvador- cuyo art. 8 refiere a los "Derechos Sindicales» como, también, a la Carta Internacional Americana de Garantías Sociales (Declaración de los Derechos Sociales del Trabajador, Bogotá, 1948). Asimismo, recordó sus precedentes en los casos ATE vs. Ministerio de Trabajo. s/ Ley de Asociaciones Sindicales (Fallos 331:2499; 2008), Rossi Adriana M. vs. Estado Nacional - Armada Argentina. s/ sumarísimo (Fallos 332:2715; 2009) y Asociación de Trabajadores del Estado s/ acción de inconstitucionalidad (Fallos: 336:672; 2013; referido al derecho de las asociaciones sindicales simplemente inscriptas para representar judicialmente los intereses colectivos de los trabajadores) para argüir el derecho de huelga corresponde tanto a asociaciones sindicales con personería gremial como a sindicatos simplemente inscriptos. Sobre este marco va a arribar a la conclusión, que «el único requisito al que el art. 14 bis de la CA supedita el ejercicio de los derechos sindicales por parte de las organizaciones de trabajadores es el de su simple inscripción 
en un registro especial, cabe concluir que el legítimo ejercicio del derecho de huelga está subordinado a que el sujeto que la dispone haya cumplido con tal recaudo de inscripción».

Esta aseveración le sirve para encuadrar el asunto en estudio, interpretando que la medida de fuerza cuestionada no había sido decidida ni dispuesta por una agrupación de trabajadores con personería gremial ni con inscripción registrada, sino motu proprio por un grupo de trabajadores. En el caso en análisis, contrariamente a lo regulado, las medidas de fuerza provinieron de grupos informales de trabajadores, razón por la cual la CSJA revocó la sentencia que había invalidado el despido y dispuso que volviera el juicio al tribunal inferior para que corrigiera su pronunciamiento y dictase un nuevo fallo que se acomodase a la interpretación arriba expuesta.

\section{DERECHO PREFERENTE DE LOS NIÑOS. HABEAS CORPUS COLECTIVO-CORRECTIVO}

El caso Recurso de hecho deducido por el Fiscal General ante la Cámara Federal de Casación Penal en la causa Cejas Meliare, Ariel s/ habeas corpus (Fallos 339-I, p. 381) llega a conocimiento de la CSJA por recurso de hecho (originado en la denegatoria del recurso extraordinario por el tribunal de sentencia final) derivado de un habeas corpus correctivo y colectivo interpuesto por la Procuración Penitenciaria de la Nación (PPN) a favor de los niños, niñas y adolescentes privados de su libertad en dependencia de la Secretaría Nacional de Niñez, Adolescencia y Familia, fundado en que esta dependencia impidió a funcionarios de la PPN a realizar visitas periódicas en sus establecimientos. Este impedimento es presentado como un agravamiento ilegítimo de las condiciones en que se cumple la privación de libertad, que se maximiza cuando se resguarda los derechos del niño quienes, como tales, gozan de una protección especial preferente. La obstrucción puesta por la autoridad controlada se interpreta entonces como un incremento real e inmediato del riesgo propio de la situación de vulnerabilidad de los menores sujetos a encierro.

El juez de primera instancia hizo lugar al habeas corpus. La Cámara Nacional de Apelaciones en lo Criminal y Correccional (Sala V) confirmó esta decisión, sin embargo, la Cámara Federal de Casación Penal (Sala III) rechazó la acción de habeas corpus y, también, el recurso extraordinario interpuesto por la Procuración Penitenciaria Nacional.

La PPN es un órgano independiente situado en el ámbito del Poder Legislativo, que tiene por objeto proteger los derechos humanos de las personas detenidas en sede ejecutiva, previéndose la penalización expresa de cualquier obstaculización de su función (arts. 1 y 21 de la Ley 25 875). Asimismo, la Ley 26.827 refrendó luego dicha función de garantía y, en especial, la facultad 
de la PPN de realizar inspecciones y de acceder a todos los lugares de detención, instalaciones y servicios, para entrevistarse sin previo aviso con las personas privadas de su libertad en establecimientos de los Estados nacional, provincial o municipal, así como en cualquier otra entidad pública, privada o mixta.

Se invoca el incumplimiento de la Ley 26827 que establece el Sistema Nacional de Prevención de la Tortura y Otros Tratos o Penas Crueles, Inhumanos o Degradantes, como normativa de desarrollo de la Convención contra la Tortura y Otros Tratos o Penas Crueles, Inhumanos o Degradantes (ratificada por Ley 23 338, que goza de jerarquía constitucional vis a vis art. 75 inc. 22 CA) complementada por el Protocolo Facultativo de la Convención contra la Tortura y otros Tratos o Penas Crueles, Inhumanos o Degradantes, aprobado por Ley 25932.

Pero, además, en este caso debe atenderse el «interés superior de niño» que impone a los tribunales considerar como criterios rectores el resguardo del desarrollo y del ejercicio pleno de sus derechos en todos los órdenes de la vida, dispensándoles un trato diferente en función de sus condiciones especiales, para lo cual el Estado argentino se comprometió a adoptar medidas positivas: entre otras, la de asegurar la protección contra malos tratos, en su relación con las autoridades públicas, conforme a los arts. 3, 17, 19 y 37 de la Convención sobre los Derechos del Niño, que goza de jerarquía constitucional por el art. 75 inc. 22 CA, que, también, según las Reglas de las Naciones Unidas para la Protección de los Menores Privados de su Libertad (Reglas 14 y 72) no pueden restringirse o debilitarse bajo ninguna circunstancia (véase arts. 5 y 41, Ley 26 827). Concordante además, con otros tratados internacionales incorporados al derecho interno con jerarquía constitucional (art. 5 de la Declaración Universal de Derechos Humanos; arts. 7 y 10 del Pacto Internacional de Derechos Civiles y Políticos; art. 5 de la Convención Americana sobre Derechos Humanos).

Con cita de jurisprudencia de la Corte Interamericana, la Corte señala que el interés superior de los niños privados de libertad impone así al Estado la obligación de adoptar medidas especiales y de obrar con el mayor cuidado y responsabilidad, en función de la debilidad, el desconocimiento y la indefensión que aquellos presentan (Corte Interamericana de Derechos Humanos: Bulacio vs. Argentina, párrafo 126; Niños de la Calle -Villagrán Morales y otros- vs. Guatemala, párrafos 146 y 191; Hermanos Gómez Paquiyauri vs. Perú, párrafos 124, 163 y 164; Instituto de Reeducación del Menor vs. Paraguay, párrafo 160; Mendoza y otros vs. Argentina, párrafo 188). La inobservancia de estas premisas comprometería la responsabilidad internacional del Estado argentino. 
Por otra parte, advierte que la especial naturaleza del habeas corpus exige la adopción de un criterio de admisibilidad en el que las exigencias formales no supongan un obstáculo para impedir que la Corte Suprema se pronuncie respecto de la posible violación de los derechos fundamentales que la acción está llamada a tutelar.

En resumen, concluye que la obstrucción puesta por la autoridad penitenciaria a la actividad del PPN, que es una institución independiente y con facultades legales preexistentes, constituye, en el seno de un dispositivo de control cruzado, un incremento real e inmediato del riesgo propio de la situación de vulnerabilidad de los niños, niñas y adolescentes sujetos a encierro, que amerita su solución por la vía del habeas corpus presentado. En consecuencia, la CSJA procede a hacer lugar a la acción de habeas corpus correctivo y colectivo en favor de los niños, niñas y adolescentes que se encuentran privados de su libertad y ordena que vuelva al tribunal de origen para que dicte un nuevo pronunciamiento con arreglo a lo resuelto, o sea, que imponga a la autoridad administrativa la obligación de autorizar la visita, inspección y control del PPN.

\section{OTROS CASOS}

\section{EXTRADICIÓN DE TERRORISTA}

Caso Quispe Caso, Oswaldo Ceferino s/ Extradición (art. 54, Código de procedimientos penales de la Nación) (Fallos 339:591).

La República del Perú, solicitó la extradición de Oswaldo Ceferino Quispe Caso imputado de haber cometido, siendo integrante de la organización terrorista «Sendero Luminoso», un acto de terrorismo que tuvo lugar el 9 de julio de 1989 en Perú, con la toma de un vehículo de transporte interprovincial y la muerte de los efectivos policiales Mauro Lagoitía Escurra y Jaime Casa Pucapuca.

El juez federal de primera instancia rechazo el pedido por considerar que faltaba precisión a la base fáctica de la cual se lo acusa, así como tampoco se advertirían garantías suficientes que serán respetados sus derechos a un debido proceso y se resguardará su integridad física. Contra esa decisión Perú interpuso recurso ordinario ante la CSJA.

Por un lado, los hechos alcanzados por la imputación extranjera fue aclarada en el «Informe Complementario» expuesto por la Sala Penal Nacional de la República del Perú. Asimismo, por una parte, esa delimitación fáctica halla concordancia con el encuadre legal (art. 228-B del Código Penal) sobre el que se sustentó la imputación extranjera en el pedido de extradición, lo que, por 
otra parte, encuadra según el derecho argentino y a los fines del principio de «doble incriminación», en los arts. 79 y 210 bis del Código Penal argentino.

Por otro lado, los reparos sobre el valor probatorio de actos procesales sustanciados en extraña jurisdicción la Corte entiende que deben ser esgrimidos en el proceso que se sustancia en la República del Perú.

Finalmente, en lo que se refiere al riesgo de que Quispe Caso sufra por parte de las autoridades requirentes un trato incompatible con los estándares internacionales de derechos humanos, resultan aceptables los numerosos esfuerzos del país requirente por subsanar las falencias acusadas e incorporar a su ordenamiento jurídico las reformas sugeridas por el organismo internacional («Observaciones finales sobre los informes periódicos quinto y sexto combinados del Perú, aprobadas por el Comité en su $49^{\circ}$ período de sesiones (29 de octubre a 23 de noviembre de 2012)», CAT/C/PER/CO/5-6, distribuida el 21 de enero de 2013).

Sobre la concordancia de las condiciones de detención compatibles a las vigentes en la legislación argentina, además de garantizar que se computará en el proceso de origen el tiempo que permanezca detenido, la CSJA entiende que la Sala Penal en lo Nacional de la República del Perú brindó, en el "Informe Complementario», condiciones satisfactorias, que permiten dar por cumplidas los recaudos del tratado de extradición con la República del Perú (Ley 26 082), en cuanto el extraditurus cuenta con garantías de que será respetado su derecho a un debido proceso en el país requirente.

Finalmente, la CSJA resuelve hacer lugar al recurso de apelación ordinaria interpuesto por la República del Perú, revocar la resolución del a quo y declarar procedente el pedido de extradición formulado por ese país respecto de Oswaldo Ceferino Quispe Caso para ser sometido a proceso por los hechos en que se sustentó este pedido de extradición.

\section{SISTEMA DE CONTROL DIFUSO DE CONSTITUCIONALIDAD}

Caso Coto centro integral de comercialización S.A. vs. Santa Fe, provincia de s/ Amparo (Fallos 339-I, pp. 525). A través de un amparo una empresa comercial solicita la declaración de inconstitucionalidad de una ley provincial que regula la jornada de trabajo y el descanso semanal de los trabajadores y el régimen de apertura y cierre de supermercados.

Este caso es muy revelador porque le da ocasión a la CSJA para reafirmar dos clásicas doctrinas. La primera para recordar la tradicional posición de la Corte que solo tiene jurisdicción originaria materia cuando una provincia es parte, cuando en razón de la materia la acción entablada se funda directa y exclusivamente en prescripciones constitucionales de carácter nacional, leyes del Congreso, o tratados, de tal suerte que la cuestión federal sea la predominante en la 
causa; en consecuencia, no procede esta competencia de excepción cuando un estado provincial es demandado por cuestiones de índole local que traigan aparejada la necesidad de analizar normas locales o actos administrativos de las autoridades provinciales, legislativos o judiciales de carácter local.

En segundo lugar, para ratificar el modelo difuso de control judicial de constitucionalidad en Argentina, con estos términos: «La atribución que tienen y el deber en que se hallan los tribunales de justicia locales de examinar las leyes en los casos concretos que se plantean, comparándolas con el texto de la CA para averiguar si guardan o no conformidad con esta, y abstenerse de aplicarlas, si se encuentran en oposición con ella», en consecuencia, concluye: "Tal estado de cosas trae aparejado que no exista óbice para que todo magistrado argentino, federal, nacional o provincial, sea cual fuere su competencia, se pronuncie sobre las cuestiones constitucionales que pudiesen proponerse en los asuntos que deba juzgar, en virtud de la naturaleza difusa del control de constitucionalidad que ejercen todos los jueces del país, de nuestro sistema federal y de las autonomías provinciales».

\section{CONFLICTO ENTRE PODERES PROVINCIALES}

La Argentina, a nivel federal, carece de una vía procesal independiente para resolver los conflictos entre órganos constitucionales como lo tiene México, Perú o Bolivia. Estas cuestiones se canalizan a través de procedimientos contencioso-administrativos en tribunales de primera instancia, o, si se logra encuadrar en una cuestión constitucional, se emplea el amparo o la acción declarativa de inconstitucionalidad.

Estos conflictos institucionales, en cambio, encuentran solución en la mayoría de los Estados provinciales a través de la acción de inconstitucionalidad que se tramita directamente ante el Tribunal Superior de Justicia local.

Sin embargo, llegó a la CSJA un caso de conflicto de poderes en una provincia argentina, en el caso Recurso de hecho deducido por la demandada en la causa Gobernador de la Provincia de La Pampa, Oscar Mario Jorge vs. Cámara de Diputados de la Provincia de La Pampa s/ acción declarativa de certeza (Fallos 339:182). El Tribunal Superior de Justicia estadual había resuelto un conflicto suscitado entre el gobernador y la Cámara de Diputados de la provincia de La Pampa con motivo de la interpretación de las facultades de veto reconocidas a aquel en el art. 70 de la Constitución local. El resultado adverso a la demandada llevó a presentar un recurso extraordinario ante la CSJA, el que denegado por Superior Tribunal local, llevó a aquella a presentar un recurso de hecho ante la CSJA.

La CSJA cita inveterada jurisprudencia que sostiene que el Tribunal carece de jurisdicción para entender respecto de las cuestiones que, según su 
esencia, constituyen conflictos de poderes locales (Fallos 259: 11; Fallos: 328: 1689; Fallos 331: 810). En abono de esta posición recuerda que ello es así, porque en la reforma constitucional de 1860 se suprimió de la CA la atribución que confería a esta Corte jurisdicción para conocer y decidir los conflictos entre los diferentes poderes públicos de una misma provincia.

En consecuencia, señala que la protección y vigencia de las garantías deben buscarse dentro de los diversos resortes institucionales que existan en la respectiva jurisdicción y por ello los conflictos entre autoridades locales deben hallar solución — jurídica y política - en el ámbito provincial, sin injerencia de la justicia de la nación (Fallos: 136: 147; 264: 7; 291: 384; González, 1897: 770-771)), por tanto, porque el asunto no constituye una cuestión justiciable que justifique la intervención de esta Corte Suprema con arreglo a lo dispuesto en los arts. 31 y 116 de la CA, en el art. 2 de la Ley 27, y en el art. 14 de la Ley 48, concluye por desestimar a queja.

\section{CASO NISMAN}

El tema de gran repercusión social fue el caso Nisman sobre la muerte en circunstancias extrañas de este fiscal federal que investigaba el ataque terrorista que provocó la muerte de ochenta y cinco personas ocurrido del 18 de julio de 1994 en la sede de la AMIA (Asociación Mutual Israelita Argentina) en Buenos Aires.

El caso tiene aún hoy enorme repercusión mediática, no solo por el tema en sí que este fiscal federal investigaba (acto de terrorismo que involucra un Estado extranjero, Irán, con conexiones locales más las consiguientes dificultades de esclarecer el hecho y determinar los responsables, algunos con relevantes cargos políticos) sino las circunstancias en que ocurrió su muerte.

En la Ciudad Autónoma de Buenos Aires, capital federal de la República Argentina, conviven dos clases de tribunales, unos con competencia federal y otros con competencia ordinaria. Ambos dependen del Estado nacional, designados por el presidente con acuerdo del Senado previa selección por concurso del Consejo de la Magistratura. En suma, aunque con ámbitos competenciales diferentes (unos atiende cuestiones federales y otros - análogamente a los tribunales provinciales - se ocupan de cuestiones ordinarias: civiles, comerciales, laborales, penales en la jurisdicción de la ciudad de Buenos Aires) comparten el mismo espacio territorial en la capital federal.

La muerte del fiscal federal Nisman se presentó inicialmente como un caso de suicidio razón por la cual intervino en primer lugar la justicia penal ordinaria (nacional) de la ciudad de Buenos Aires (en la jerga judicial se denominan tribunales «nacionales» para diferenciarlos de los tribunales «federales»). 
Sin embargo, por tratarse de la persona de un fiscal federal, en razón de su investidura como funcionario federal, se planteó una cuestión de competencia entre estos dos ámbitos judiciales que llegó hasta la intervención de la Corte Suprema argentina (que opera como tribunal superior para los conflictos de competencia que ocurren entre tribunales nacionales y federales dentro de la ciudad de Buenos Aires).

El asunto llega a su decisión en la causa Recurso de hecho deducido por el Fiscal General ante la Cámara Nacional de Apelaciones en lo Criminal y Correccional en la causa N.N. y otros s/ averiguación de delito - Damnificado: Nisman, Alberto y otros (Fallos 339-II, 1344), por la cual, el juez nacional que primero intervino, planteó una declinatoria de competencia a favor de la jurisdicción federal, la que fue avalada por la Cámara Nacional de Apelaciones en lo Penal. Esta decisión (de pasar la causa al fuero federal) fue cuestionada por uno de los involucrados en el hecho que pretendía que el asunto se investigase por los tribunales nacionales (ordinarios) de la capital federal. La Cámara Nacional de Casación Penal por el carácter excepcional de la jurisdicción federal sostuvo que la investigación correspondía a los tribunales ordinarios de la ciudad.

Finalmente, la CSJA resolvió a favor de la competencia federal la investigación del hecho porque "persiste (o no ha sido descartada) la hipótesis de la vinculación del hecho investigado con las tareas concretas que realizaba en ejercicio de su función el Fiscal federal al momento de su deceso»y, en base a precedentes entendió que «en la medida en que las constancias de la causa no permitan descartar una hipótesis que refiera a un delito cometido en perjuicio de un funcionario federal (en el precedente citado [Fallos: 250:391], un legislador nacional) corresponde que sea la justicia federal la que investigue el caso», ello es así porque «es doctrina inveterada de este Tribunal la competencia federal con relación al juzgamiento de delitos comunes cometidos contra o por funcionarios federales en ejercicio de sus tareas».

En tanto que aquí solo se dirime una cuestión de competencia, para poner en resguardo la posible futura intervención de la Corte sobre el fondo del asunto va prevenir

que, por cierto, al menos hipotéticamente, no sería posible descartar de plano la posibilidad de que la muerte del fiscal Nisman hubiera sido fruto de su propia decisión libre y voluntaria, y sin ninguna intervención de terceros. Sin embargo, aun en ese caso, la evidente incidencia en el normal desarrollo de investigaciones federales y las presuntas motivaciones del hecho - que en cualquiera de los supuestos que se examinan en este proceso penal no parecen ser extrañas a la función desempeñada por el Dr. Nisman - imponen que sea el fuero de excepción el que continúe conociendo en el sumario, en efecto, «se encuentra fuera de discusión la relevancia 
institucional de la investigación del caso AMIA que el fiscal Nisman tenía a su cargo como así también que al producirse su fallecimiento se encontraba abocado a esa tarea», precisamente, por ello, "la circunstancia de que la víctima estuviera cumpliendo tareas específicamente federales ha constituido un punto de contacto constante para la declaración de la competencia en favor del fuero federal». En consecuencia, la CSJA, con la firma unánime de sus cinco miembros, procedió a la revocación de la sentencia apelada, y a la declaración de la competencia federal de modo que sea la justicia federal la que asuma el conocimiento e investigación de este resonante caso.

\section{Bibliografía}

González, J. V. (1897). Manual de la Constitución argentina. Buenos Aires: Estrada. 